\title{
The stray bullet
}

\begin{abstract}
In the case of a bullet fired at a precisely vertical angle, it immediately begins to slow down because of the effects of gravity and air drag on the bullet. The bullet deceleration continues until at some point the bullet momentarily stops and then it begins to fall back toward earth. The bullet speed will increase during its free fall until it reaches its terminal velocity i.e. the bullet weight and air drag is balanced. Once this velocity is achieved the bullet will fall no faster and such a bullet would tumble, lose its spin, and fall at a much slower speed due to terminal velocity and therefore it may be less than lethal on impact. A man and his friend were on their way to nearby village to take dinner in a religious program. Suddenly the man was hit by a bullet on the top of his shoulder and he died. A case was registered U/S 302IPC. Careful scientific investigation reveals that it is the bullet fired by someone in air which on return journey towards earth hit the man.
\end{abstract}

Volume I Issue I - 2015

\section{Sharma DK,' Sandeep Tomar ${ }^{2}$ \\ 'District Scene of Crime Unit, India \\ ${ }^{2}$ Regional Forensic Science Laboratory, India}

Correspondence: Sharma DK, District Scene of Crime Unit, E-8/9 Char- Imli, Bhopal, India, Tel +9I-9826346600, Email dksharmafsı@gmail.com

Received: July 10, 2015 | Published: August II, 2015

Keywords: soft nose bullet, stray bullet, velocity, spin, gravity, injury

\section{Introduction}

In many parts of the world including India bullets are fired in air to celebrate some occasion such as New Year, child birth, victory etc. On returning to earth they may fall on someone though the probability is very rare. The extents of injuries caused by such bullets are found quite different. The victim may be severely injured or killed. Sometimes such injury may be quite superficial also. Property damage, particularly holes in roof is another result .The expansion of cities and increase in population density coupled with increasing tendency to fire in air results in dramatic rise in such cases in present times. The practice of shooting in air to celebrate something is very common in Gwalior and Chambal Division of Madhya Pradesh in general and Gwalior district in particular. Every year some cases of this type are reported in Gwalior district. One such case is discussed in the present paper.

\section{Case report}

\section{History}

In the evening of 25/5/2007 deceased Balkishan and his friend Chakrapal were on their way to village Gunaya to take dinner in Bhagawat (a religious program). They were on bicycles and Balkishan was just behind Chakrapal. At the place called Jhindora Nala Balkishan came near to Chakrapal and told him that something hit the upper part of his shoulder and then he fell dead.

\section{At scene}

The spot was the dusty way of countryside which was used by the villagers for transportation. The area surrounding the spot was almost plane without any tall tree and high-rise structure. The deceased's friend Chakrapal told during the spot inspection that he could not hear any sound of gunfire at the time of incidence (Figure 1).

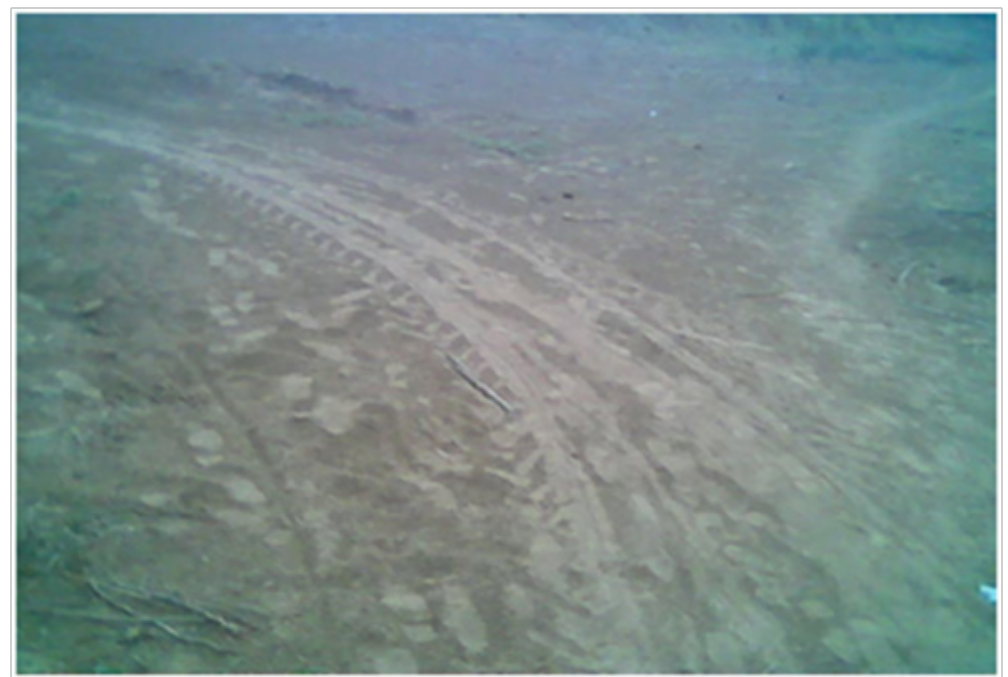

Figure I The area surrounding the spot was almost plane without any tall tree and high-rise structure.

\section{Result and discussion}

The deceased was hit by the bullet on the top of his left shoulder and there were holes found in his baniyan and kurta at that place.
There was no burning, blacking and tattooing around the wound and on the clothes. This eliminates the possibility of firing from close range. Autopsy revealed that the bullet traveled almost straight from upper to lower part of the body without any exit wound but the area 
surrounding the spot was almost plane, without any tall tree and high-rise structure Figure 2. It seems quite impossible that a gun fired from such a plane place could results in an injury like this in normal circumstances. Secondly the deceased's friend Chakrapal who was present during the incidence also told that he could not hear any sound of gunfire at the time of incidence. It means the bullet was fired from a distance too far for the shot to be heard. It is a well known fact that a rifle bullet fired upward in air at a non vertical angle follows a parabola path and covers a long distance. Further a soft nose bullet of $8 \mathrm{~mm}$ caliber having six right handed land and grooves was recovered from the body during postmortem. The caliber and number of land and grooves present on the bullet shows that it was fired by some standard .315 caliber company made rifle. This rifle produce quite prominent sound when fired i.e. the sound of its fire can't be unnoticed. Further bullet fired from such a rifle can cover a very long distance. On the basis of above findings it can be concluded that the bullet was fired by someone in air with standard .315 caliber company made rifle and on its return journey it hit the upper side of the man's shoulder. However, if a bullet is fired upward at a non-vertical angle (a far more probable possibility), it will maintain its spin and will have a high enough speed to be lethal on impact. A bullet travelling at only 150 feet per second $(46 \mathrm{~m} / \mathrm{s})$ to 170 feet per second $(52 \mathrm{~m} / \mathrm{s})$ can penetrate human skin, ${ }^{1}$ and at less than 200 feet per second $(60 \mathrm{~m} / \mathrm{s})$, it can penetrate the skull. ${ }^{2}$ A bullet that does not penetrate the skull may still result in an intracranial injury. ${ }^{3}$ Because of this potentiality, firing a gun into the air is illegal in many parts of world. People are injured, sometimes fatally, when bullets discharged into the air fall back down. The mortality rate among those struck by falling bullets is about $32 \%$, compared with about $2-6 \%$ normally associated with gunshot wounds. ${ }^{4}$ A study by the U.S. Centers for Disease Control and Prevention (CDC) found that $80 \%$ of celebratory gunfire-related injuries are to the head, feet, and Shoulders. ${ }^{5}$ The higher mortality is related to the higher incidence of head wounds from falling bullets. First noted case of stray bullet death in India is way back to December 1859: An autopsy showed a servant, who suddenly fell dead for no apparent reason, was mortally wounded from a bullet fired from a distance. The falling bullet had sufficient energy to pass through the victim's shoulder, a rib, a lung, his heart and diaphragm. ${ }^{6}$ between the years 1985-1992, doctors at the King/Drew Medical Center in Los Angeles, California treated some 118 people for random falling-bullet injuries 38 of them died. ${ }^{7}$ Kuwaitis celebrating in 1991 at the end of the Gulf War by firing weapons into the air caused 20 deaths from falling bullets. ${ }^{7}$

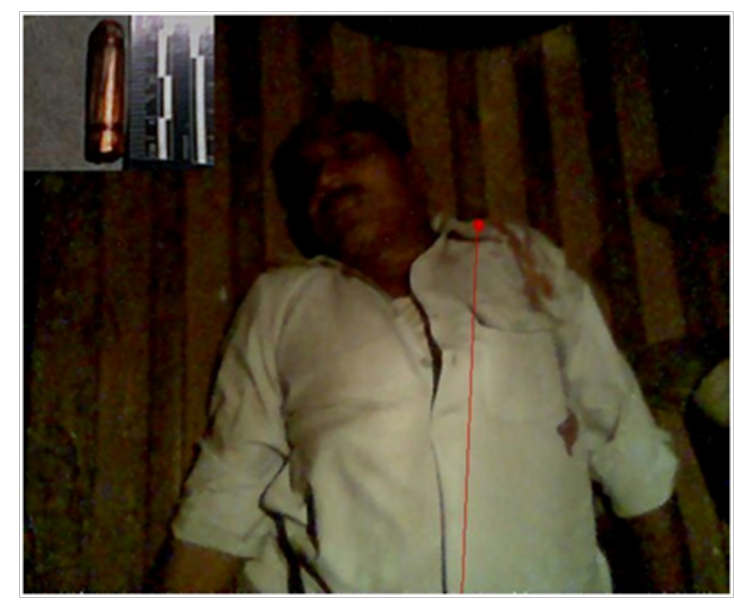

Figure 2 Autopsy revealed that the bullet traveled almost straight from upper to lower part of the body without any exit wound but the area surrounding the spot was almost plane, without any tall tree and high-rise structure.

\section{Conclusion}

On the basis of all above facts it can be concluded that the bullet fired by someone in air with standard .315 caliber company made rifle hit the upper side of the man's shoulder on return journey towards earth. The practice of firing in air should be strictly banned.

\section{Acknowledgments}

None.

\section{Conflicts of interest}

The author declares that there are no conflicts of interest.

\section{References}

1. Stewart Michael G Head, Face, Neck Trauma. Comprehensive Management. Thieme Medical Publishers, New York. 2005;189.

2. Fourth of July Gunfire Reduction Program. Official web site of the Los Angeles Police Department.

3. Adam SK, Osborne S. Critical care nursing: science and practice. $\left(2^{\text {nd }}\right.$ edition), Oxford University Press, Oxford, UK. 2005;537.

4. Ordog GJ, Dornhoffer P, Ackroyd G, et al. Spent bullets and their injuries: the result of firing weapons into the sky.J Jrauma. 1994;37(6):1003-1006.

5. Puerto Rico. New Year's Eve Injuries Caused by Celebratory Gunfire. 2003;53(50):1174-1175.

6. Longmore T. Gunshot Injuries, Their History, Characteristic Features, Complications, and General Treatment: with statistics concerning them as they have been met in warfare. ( $2^{\text {nd }}$ edition). 1895.

7. Incorvaia AN, Poulos DM, Jones RN, et al. Can a Falling Bullet Be Lethal at Terminal Velocity? Cardiac Injury Caused by a Celebratory Bullet. Ann Thorac Surg. 2007;83(1):283-284. 